\title{
PCB Uptake and Transfer to Humans by Lake Trout
}

\author{
A. L. Jensen \\ School of Natural Resources, University of Michigan, \\ Ann Arbor, Michigan 48109, USA
}

\begin{abstract}
$A B S T R A C T$
A mathematical model for contaminant uptake from food and water by fishes is combined with a model for yield as a function of fishing mortality in order to examine both the contaminant concentration in fishes and the amount of contaminant transferred to humans from fishes as functions of fishing mortality. The models are fitted to lake trout Salvelinus namaycush data from Lake Michigan, where there has been a persistent problem of $P C B$ contamination. Transfer of contaminants from fishes to humans can be regulated through control of fishing. The concentration of contaminant decreases exponentially as fishing mortality increases because fishing reduces the number of older individuals in the population and concentration is a function of age. The amount of contaminant transferred from a fish population to humans increases to a maximum and then begins to decrease as fishing effort increases. The maximum rate of transfer occurs at a relatively low level of fishing.
\end{abstract}

\section{INTRODUCTION}

Concern with contamination of fishes has resulted in modelling efforts to describe and understand contaminant transfer, biomagnification and fate. Considerable progress has been made and models have been successfully developed and applied (Norstrom et al., 1976; Neely, 1977; Schnoor, 1981; Thomann, 1981; Jensen et al., 1982). One important aspect of the dynamics of contaminants that has not been examined is the impact of fishing on the contaminant concentration in fish consumed by humans and on the amount transferred to humans.

Entiron. Pollut. Ser. A. 0143-1471/84/\$03.00 C Elsevier Applied Science Publishers Ltd, England, 1984. Printed in Great Britain 
The concentration of contaminants in fishes such as lake trout Salvelinus namaycush is a function of age, and fishing has a large impact on the age structure and therefore on the average concentration of contaminants in lake trout. In this study the Norstrom et al. (1976) bioenergetic model for uptake of contaminants and the Beverton \& Holt (1957) dynamic pool yield model are combined to simulate the mean concentrations of PCBs in lake trout of Lake Michigan and to simulate the amounts transferred to humans as a function of fishing effort. It is shown that increased fishing can reduce both the contaminant concentration in fish and the amount transferred from fish to humans. These results are important for design of controls on fishing that are intended to reduce exposure to contaminants and for design and interpretation of results from monitoring programmes when there is variation in fishing effort.

\section{THE MODEL}

The quantity of contaminant transferred annually from a contaminated fish population to humans is

$$
T=\int_{x_{\mathrm{r}}}^{x_{\mathrm{v}}} C(x) Y(x) \mathrm{d} x
$$

where

$T=$ total amount transferred (grams or kilograms per year)

$C(x)=$ concentration of contaminant in fish of age $x$

$Y(x)=$ yield from fishery of fish of age $x$

$x_{\mathrm{r}}=$ age at recruitment into the fishery

$x_{\mathrm{v}}=$ oldest age attainable by fish

The average concentration of the contaminant in the catch, $\bar{C}$, is

$$
\bar{C}=\int_{x_{r}}^{x_{v}} C(x) Y(x) d x / \int_{x_{r}}^{x_{v}} Y(x) d x
$$

and the concentration in an average fish of age $x$ is

$$
C(x)=P(x) / W(x)
$$

where $P(x)$ is the average body burden of an individual of age $x$ and $W(x)$ is the average weight of an individual of age $x$. 
To apply these equations, body burden, yield and individual weight must be determined as functions of age. Norstrom et al. (1976) modelled change in body burden as a function of age with the bioenergetics-based mass balance equation

$$
\mathrm{d} P / \mathrm{d} t=e_{\mathrm{pf}} C_{\mathrm{f}} R+e_{\mathrm{pw}} C_{\mathrm{w}} V-k P W^{\xi}
$$

where

$P=$ body burden of pollutant in fish $(\mathrm{g})$

$W=$ wet weight of fish $(\mathrm{g})$

$e_{\mathrm{pf}}=$ efficiency of assimilation of pollutant from food

$e_{\mathrm{pw}}=$ efficiency of assimilation of pollutant from water

$C_{\mathrm{f}}=$ concentration of pollutant in food $\left(\mathrm{g} \mathrm{g}^{-1}\right)$

$C_{\mathrm{w}}=$ concentration of pollutant in water $\left(\mathrm{g} \mathrm{g}^{-1}\right)$

$R=$ ration, rate of consumption $\left(\mathrm{g}\right.$ week $\left.{ }^{-1}\right)$

$V=$ rate of water flow past the gills $\left(\mathrm{g}^{-1} \mathrm{wek}^{-1}\right)$

$k=$ clearance coefficient $\left(\mathrm{g}^{-\xi}\right.$ week $\left.^{-1}\right)$

$\xi=$ exponent of body weight in the clearance term

An expression for ration was developed from the energy balance equation

$$
e_{\mathrm{f}} q_{\mathrm{f}} R=Q+q_{\mathrm{a}} \mathrm{d} W / \mathrm{d} t
$$

where

$e_{\mathrm{f}}=$ efficiency of assimilation of metabolisable energy from food

$q_{\mathrm{f}}=$ joule equivalent of food $\left(\mathrm{J} \mathrm{g}^{-1}\right)$

$q_{\mathrm{a}}=$ joule equivalent of animal accumulating pollutant $\left(\mathrm{J} \mathrm{g}^{-1}\right)$

$Q=$ total metabolic rate $\left(\mathrm{J}_{\text {week }}{ }^{-1}\right)$

Norstrom et al. (1976) separated total metabolic rate into a low routine metabolic rate $Q_{\mathrm{lr}}$, which includes the standard metabolic rate and the energy cost of spontaneous activity, and into the energy cost specific to utilisation of food, $Q_{\mathrm{s}}$. Application of the conventional metabolic expressions $Q_{\mathrm{lr}}=\alpha W^{\gamma}$ and $Q_{\mathrm{s}}=\beta q_{\mathrm{a}} \mathrm{d} W / \mathrm{d} t$ for these components gives

$$
R=\frac{1}{e_{\mathrm{f}} q_{\mathrm{f}}}\left[\alpha W^{\gamma}+q_{\mathrm{a}}(1+\beta) \mathrm{d} W / \mathrm{d} t\right]
$$

An expression for the volume of water passing the gills is found from the relation between the amount of oxygen necessary to satisfy metabolic 
demand and the volume of water containing this quantity of oxygen, which is

$$
Q=e_{\mathrm{ox}} C_{\mathrm{ox}} q_{\mathrm{ox}} V
$$

where

$e_{\mathrm{ox}}=$ efficiency of assimilation of oxygen by the gills

$C_{\mathrm{ox}}=$ concentration of oxygen in the water $\left(\mathrm{g} \mathrm{g}^{-1}\right)$

$q_{\mathrm{ox}}=$ joule equivalent of oxygen $\left(\mathrm{J} \mathrm{g}^{-1}\right)$

Application of the expression for $Q$ given above (eqn. (7)) gives

$$
V=\frac{\alpha W^{\gamma}+\beta q_{\mathrm{a}} \mathrm{d} W / \mathrm{d} t}{e_{\mathrm{ox}} C_{\mathrm{ox}} q_{\mathrm{ox}}}
$$

Substitution of the expressions for $V$ and $R$ into the mass balance equation gives

$$
\begin{aligned}
\mathrm{d} P / \mathrm{d} t= & \frac{e_{\mathrm{pf}} C_{\mathrm{pf}}}{q_{\mathrm{f}} e_{\mathrm{f}}}\left[\alpha W^{\gamma}+q_{\mathrm{a}}(1+\beta) \mathrm{d} W / \mathrm{d} t\right] \\
& +\frac{e_{\mathrm{pw}} C_{\mathrm{w}}}{e_{\mathrm{ox}} C_{\mathrm{ox}} q_{\mathrm{ox}}}\left[\alpha W^{\gamma}+\beta q_{\mathrm{a}} \mathrm{d} W / \mathrm{d} t-k P W^{\xi}\right]
\end{aligned}
$$

Yield is modelled using the Beverton \& Holt (1957) dynamic pool yield equation:

$$
\begin{aligned}
\mathrm{d} Y / \mathrm{d} t & =F N(t) W(t) \\
\mathrm{d} N / \mathrm{d} t & =-(F+M) N(t), \quad t>t_{\mathrm{r}}
\end{aligned}
$$

where

$Y=$ yield from the fishery

$F=$ fishing mortality coefficient

$M=$ natural mortality coefficient

$N(t)=$ abundance of individuals of age $t$

$W(t)=$ weight of individuals of age $t$

Growth in both the yield and contaminant uptake models was described with von Bertalanffy's equation:

$$
\begin{aligned}
W(t) & =W_{\infty}\left(1-e^{-K t}\right)^{b} \\
\mathrm{~d} W / \mathrm{d} t & =b k W_{\infty} e^{-K t}\left(1-e^{-K t}\right)^{b-1}
\end{aligned}
$$


The Norstrom et al. (1976) model was fitted to the lake trout PCB data for the Wisconsin waters of Lake Michigan by Jensen et al. (1982). For completeness some details of the model fitting and calculations are described here.

Measurements of PCBs and total lengths of lake trout collected from Wisconsin waters of Lake Michigan were reported by the Wisconsin Department of Natural Resources (Scheffy, 1977). Observations were for the years 1974 to 1977 when PCB concentrations were relatively constant; a regression of PCBs against time was not significant. Eighty-nine PCB and length measurements were available.

Growth parameters were initially estimated with data summarised by Carlander (1969) but his observations were made before the increase in alewife abundance that occurred in the late 1960s; and the growth rates were too low so the growth parameters were therefore adjusted slightly to predict weights that have been observed more recently in Lake Michigan (Bails \& Patriarche, 1974). The length-weight relation was $\log _{10} W=$ $-5 \cdot 39+3 \cdot 12 \log _{10} L$ and the estimates of the growth parameters were $W_{\infty}=7.34 \mathrm{~kg}$ and $K=0.14 \mathrm{yr}^{-1}$.

Estimates of PCB concentrations in the waters of Lake Michigan vary from 1 to $13 \mathrm{ng}$ litre $^{-1}$ (Neely, 1977); $10 \mathrm{ng}$ litre $^{-1}$ was used. Alewife Alosa pseudoharengus is the principal food of larger lake trout; lake trout feed mainly on alewife after reaching about 500 to $600 \mathrm{~g}$ (Wright, 1968). The PCB concentration of alewife in Lake Michigan averaged $3 \mathrm{mg} \mathrm{kg}^{-1}$ (Scheffy, 1977).

Estimates of the parameters $\beta, e_{\mathrm{pf}}, q_{\mathrm{ox}}, \xi, e_{\mathrm{w}}, \alpha$, and $e_{\mathrm{f}}$ were obtained from Norstrom et al. (1976, Table 1) and Jensen et al.(1982, Table 1). The (1969).

parameter $\gamma$ was set at 0.92 , which is the average reported by Glass

Age at recruitment into the fishery was set at age 4 and for simulations it was assumed that there were one million recruits. The results apply per recruitment of one million fish and not to the Lake Michigan fishery. The fishing mortality coefficient was set at 0.50 for simulations in which fishing mortality was assumed constant.

The integrals in eqns. (1), (2) and (3) were calculated with the trapezoidal rule with an interval size of 0.25 years. Yield and PCB body burdens were calculated from the differential equations by first replacing them with difference equations; calculations were made at intervals of 0.25 years. 


\section{RESULTS AND DISCUSSION}

The Norstrom et al. (1976) model predicts that contaminant concentration increases with age (Fig. 1), and this is the uptake pattern observed for fishes of the Great Lakes and for lake trout of Cayuga Lake (Bache et al., 1972; Jensen et al., 1982). The body burden increases with age but the rate of change in body burden with age decreases until about age 9 , then the rate of change in body burden begins to increase. This uptake pattern results from the growth dynamics of fishes. At younger ages the rate of growth in size is rapid and biomass accumulation maintains a lower concentration of contamination; at older ages the size of individuals begins to approach the asymptotic size and the rate of growth slows. The increasing PCB body burden of older fish is not accompanied by a corresponding increase in weight and the rate of increase in the concentration of PCBs begins to increase.

The impact of fishing on age structure and on the relation between yield per recruitment and fishing mortality are well known but they are presented here because they determine both the average concentration of contaminants in the catch of fish and the amount transferred from fish to humans. A fishery has a large impact on the age structure of a population (Fig. 2) and for long-lived species such as lake trout even a modest level of fishing causes a severe reduction in abundance of the older age groups. A fishing mortality of 0.40 nearly eliminates the older age groups from the population and this is an average level of exploitation for lake

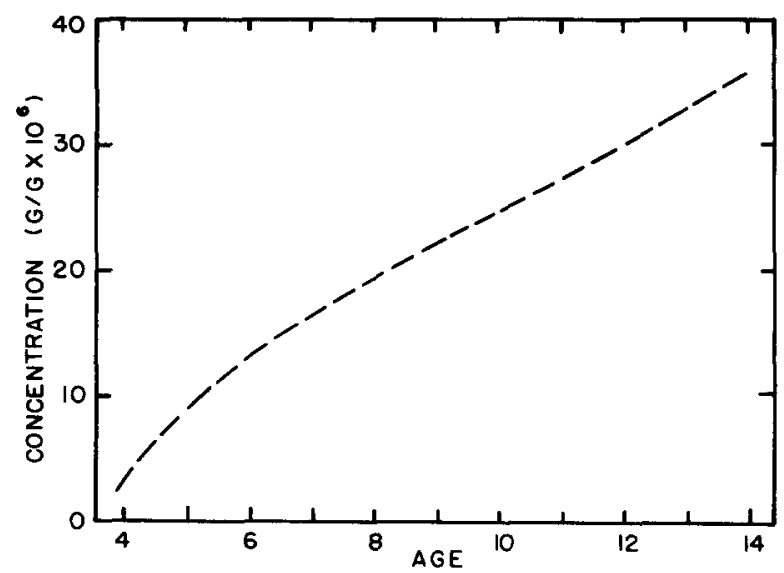

Fig. 1. $\mathrm{PCB}$ concentration as a function of age for lake trout in Lake Michigan. 


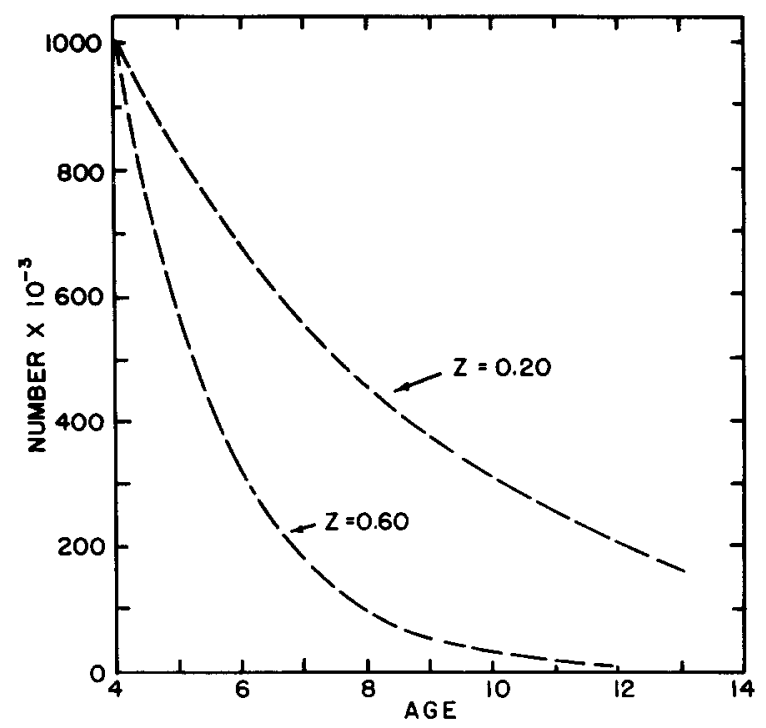

Fig. 2. Number of individuals as a function of age with a recruitment of one million and fishing mortality coefficients, $F$, of 0 and 0.40 . The natural mortality coefficient is $0 \cdot 20$ which gives total mortality coefficients, $Z$, of 0.20 and 0.60 .

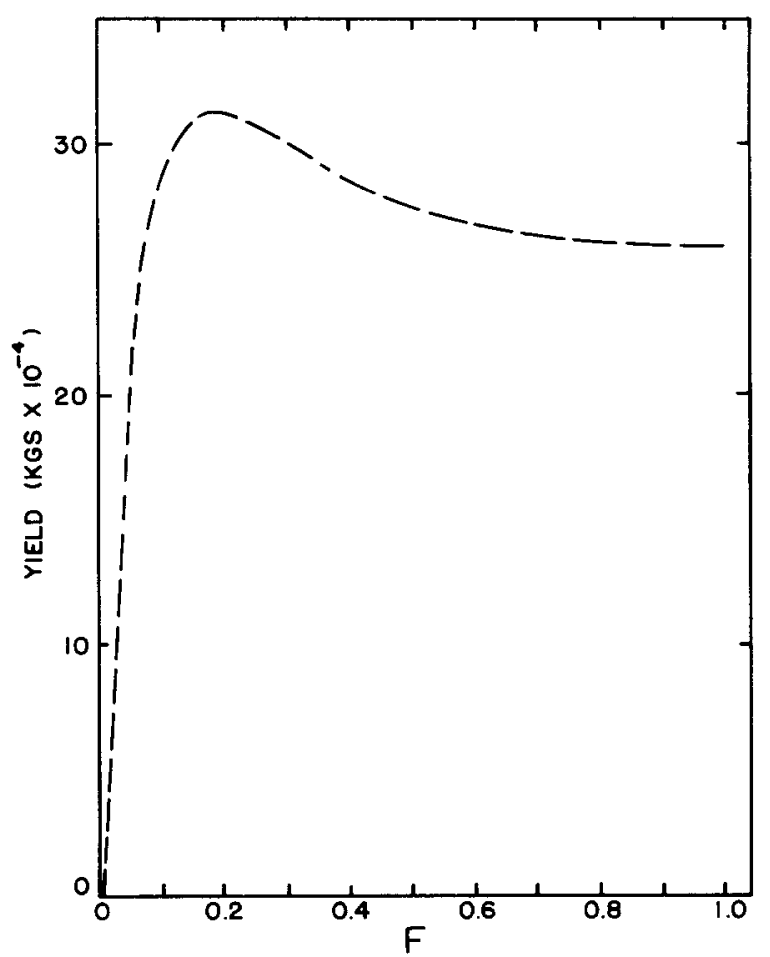

Fig. 3. Yield from the fishery as a function of fishing mortality. 


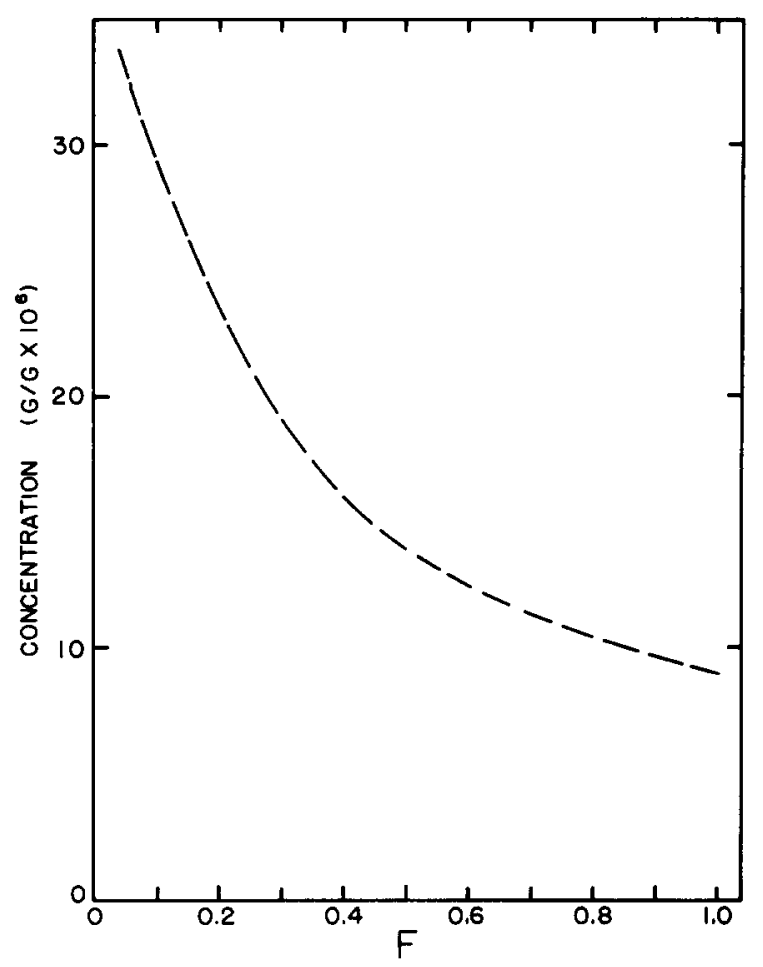

Fig. 4. PCB concentration of lake trout catch as a function of fishing mortality.

trout (Healey, 1978). If fishing mortality is high an exploited population consists mainly of newly recruited individuals. Yield from the lake trout fishery increases to a maximum at a fishing mortality coefficient of 0.2 and then slowly decreases as fishing mortality increases (Fig. 3).

The average concentration of PCBs in fish decreases exponentially with increase in the level of exploitation (Fig. 4). For an unexploited population the $\mathrm{PCB}$ concentration is $36 \times 10^{-6} \mathrm{~g} \mathrm{~g}^{-1}$. The decrease in PCB concentration with increased fishing occurs because fish are caught before they attain older ages and their exposure to PCBs is reduced. With a high level of fishing all fish are caught soon after recruitment and the PCB level is close to that for recruits which is $3 \times 10^{-6} \mathrm{~g} \mathrm{~g}^{-1}$.

The amount of PCBs transferred from the lake trout population to humans increases to a maximum and then begins to decrease as fishing mortality increases (Fig. 5). The maximum amount transferred occurs at a fishing mortality of $0 \cdot 1$, which is lower than the fishing mortality of 0.2 that produces the maximum yield per recruitment. Initially the transfer of 


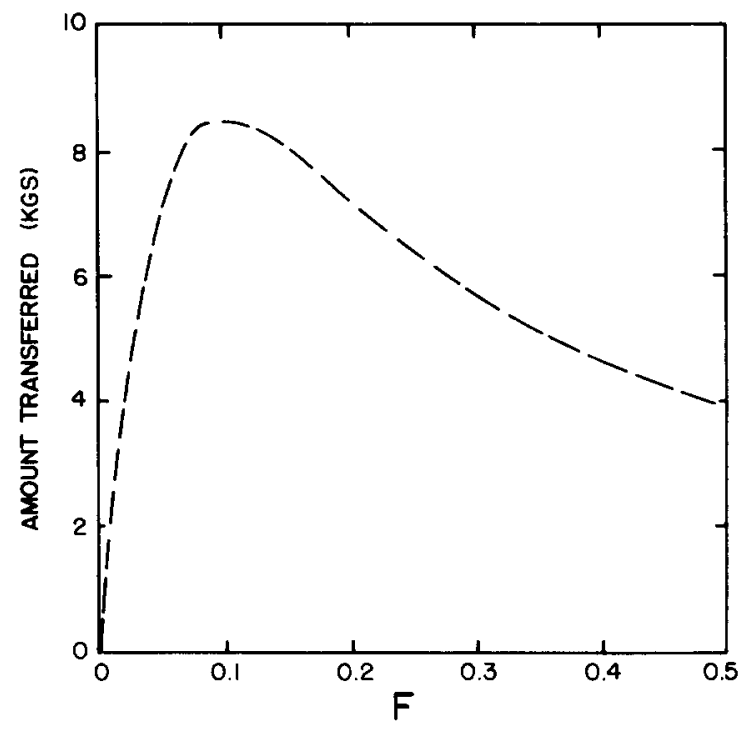

Fig. 5. Total amount of PCBs transferred from the lake trout population to humans as a function of fishing mortality.

contaminants increases as fishing mortality increases because more fish are caught, but at higher levels of fishing the change in age structure of the exploited stock results in a lower average concentration in the population and this results in a smaller amount transferred. At high levels of fishing the yield decreases and this further decreases the amount of PCBs transferred; the transfer curve (Fig. 5) decreases more rapidly than the yield curve at high levels of fishing.

The above results indicate that when a recommendation is made to reduce fish consumption in order to reduce exposure, a decrease in fishing mortality may occur, but that this could result in a higher contaminant concentration and a higher level of contaminant transfer from fish to people. Closure of a fishery can result in a build-up of contaminants.

Contaminant levels in areas where fish populations have been contaminated are often monitored. In the Great Lakes a decrease in lake trout PCB concentrations has been reported but the sampling programme is limited because of severe budgetary constraints, and adjustments for age of fish and for the impact of a changing fishery have not been made. There has been a large increase in both the sport and commercial fishery for lake trout in the Great Lakes with serious depletion of the stocks in many areas. The observed decrease in PCBs could result largely from an increase in fishing effort. 


\section{REFERENCES}

Bache, C. A., Serum, J. W., Youngs, W. D. \& Lisk, D. J.(1972). Polychlorinated biphenyl residues: accumulation in Cayuga Lake lake trout with age. Science, N.Y., 177, 1191-2.

Bails, J. D. \& Patriarche, M. H. (Eds) (1974). Status of selected fish stocks in Michigan's Great Lakes waters and recommendations for commercial harvest. Michigan Department of Natural Resources Technical Reports, 73$10,11,32$ and 33 .

Beverton, R. J. H. \& Holt, S. J. (1957). On the dynamics of exploited fish populations. U.K. Min. Agric. Fish., Fish. Invest. (Ser. 2), 19.

Carlander, K. D. (1969). Handbook of freshwater fishery biology, 1. Ames, IA, Iowa State University.

Glass, N. R. (1969). Discussion of calculations of power function with special reference to respiratory metabolism in fish. J. Fish. Res. Bd Can., 26, 2643-50.

Healey, M. C. (1978). The dynamics of exploited lake trout populations and implications for management. J. Wildl. Mgmt, 42, 307-28.

Jensen, A. L., Spigarelli, S. A. \& Thommes, M. M. (1982). PCB uptake by five species of fish in Lake Michigan, Green Bay of Lake Michigan, and Cayuga Lake, New York. Can. J. Fish. Aquat. Sci., 39, 700-9.

Neely, W. B. (1977). A material balance study of polychlorinated biphenyls in Lake Michigan. Sci. Total Environ., 7, 117-29.

Norstrom, R. J., McKinnon, A. E. \& DeFreitas, A. I. W. (1976). A bioenergeticsbased model for pollutant accumulation by fish. Simulation of PCB and methyl mercury residue levels in Ottawa River yellow perch (Perca flavescens). J. Fish. Res. Bd Can., 33, 248-67.

Scheffy, T. B. (1977). Status report on the PCB problem in Wisconsin. Madison, WI, Wisconsin Department of Natural Resources.

Schnoor, J. L. (1981). Fate and transport of dieldrin in Coralville Reservoir: residues in fish and water following a pesticide ban. Science, N.Y., 211, $840-2$.

Thomann, R. V. (1981). Equilibrium model of fate of microcontaminants in diverse aquatic food chains. Can. J. Fish. Aquat. Sci., 38, 280-96.

Wright, K. J. (1968). Feeding habits of immature lake trout Salvelinus namaycush in the Michigan waters of Lake Michigan. MS thesis, Michigan State University, East Lansing, MI. 